\title{
Comparison of the Level of Anxiety and Quality of Life among Spouses of Women with Breast Cancer and Healthy Women
}

\author{
Mahboobeh Magharei ${ }^{1,2}$, Fereshteh Dehgahanrad ${ }^{1,2} *$, Fatemeh Vizeshfar ${ }^{1,2,3}$ \\ ${ }^{1}$ Faculty member of Nursing, Shiraz University of Medical Sciences, Shiraz, Iran \\ ${ }^{2}$ Community Based Psychiatric Care Research Center, Shiraz University of Medical Sciences, Shiraz, Iran \\ ${ }^{3}$ PHD Candidate of Nursing Education, Shiraz University of Medical Sciences, Shiraz, Iran
}

\begin{abstract}
The present study examined the Level of anxiety and Quality of life among spouses of women with breast cancer and husbands of healthy women. The statistical population of the study was all of the spouses of patients with breast cancer who were under chemotherapy. Husbands of women with breast cancer $(n=95)$ and without breast cancer $(\mathrm{n}=95)$ completed self-report questionnaires including demographic information, short-form quality of life questionnaire of WHO and Beck anxiety questionnaire. Results showed that levels of anxiety in husbands of women with breast cancer in compare to spouses of healthy women were higher. Although in this study, a significant statistical difference between the overall quality of life score of spouses of women with breast cancer and healthy women were not found, but a significant difference was observed in social relationships and environment domains.
\end{abstract}

Keywords: Anxiety, Quality of life, Breast Cancer Women's Spouses.

\section{INTRODUCTION}

The most common cancer among women is breast cancer [1]. This disease is a major surgical and oncological challenge [2]. In the United States, being the second fatal cancer in women, about 182000 women are diagnosed with this type of cancer annually [3].

In Iran, according to the estimation of Health, Treatment and Medical Education Ministry, breast cancer is the most common type of cancer in Iranian women and approximately 10000 women are diagnosed annually [4]. Diagnosis of a dangerous disease such as breast cancer interferes with not only the patients' life but also the life of their relatives. In addition to the negative effects on patients' quality of life, cancer and its treatment procedures also reduce their families' quality of life, especially their spouses. Diagnosis of breast cancer in a patient leads to considerable psychological distress, anxiety, and depression for the patient's spouse [5]. A comprehensive study on women with cancer demonstrated that the standardized ratio of the probability of occurrence of anxiety disorders in these women to the overall population of women is 1.25 [6]. Women with breast cancer described the negative consequences in themselves and their close family members. Their husbands experience emotional pains and psychological problems related to their caregiving role [7].

Husbands of women with breast cancer are the main source of support for them. In this regard, Sandgren et al (2004) conducted their study on quality of life in 112 women diagnosed with breast cancer between the ages of 34 to 84, within 1 to 3 months after diagnosis. They concluded that 60 percent of these patients introduced their spouses as the main source of emotional support [8].

The repercussions of breast cancer for patients' family members and their spouses include depression, uncertainty, and anxiety [9]. Occasionally, in breast cancer cases, caregivers and patient advocates experience more severe cases of anxiety than the patient [10]. The patients' spouses with breast cancer are in charge of other responsibilities in addition to having to deal with problems related to hospitalization. Furthermore, treatment outcomes, financial difficulties and family problems such as other family members' illness and family conflicts may also be anxiety sources for these individuals [11]. 
Mahboobeh Magharei et al. "Comparison of the Level of Anxiety and Quality of Life among Spouses of Women with Breast Cancer and Healthy Women"

From the family systems theory standpoint, diagnosis of cancer in one family member affects the health and well-being of other members as well. Most spouses experience extreme tension which continues during and after the treatment after their wives are diagnosed with a deadly disease such as breast cancer [12].

With increasing amount of stress, patients' spouses suffer from deep psychological and physiologic disorders as well [13].

Perceiving the physical and psychological outcomes of breast cancer diagnosis in patients' spouses is extremely critical[14]. Problems related to treatment have major effects on qualities of caregivers' lives. Caregiving responsibility has an impact on both physical and psychological health and increases the psychological distress in caregivers [15].

Aydogan et al (2016) concluded that evaluating life quality indices are important not only in patients but also in their caregivers in order to create a coherent solution and set reasonable expectations for caregivers [16]. Iqbal et al (2001) in their study, estimated the level of stress in spouses of patients with breast cancer to be $64 \%$ [17].

Bigatti et al. (2011) conducted a study with the aim of determining coping mechanisms used by the husbands of women with breast cancer compared with healthy ones and the relationship between coping and psychological and social variables. Their findings indicated that coping mechanisms which were used by the husbands were different in these two cases and coping was related to wellbeing and this is an important point. This study proposed that simple investigations about coping mechanisms can help clinicians to identify spouses who need help [18].

In the study conducted by Grov et al (2005), the aim was examining anxiety, depression, and quality of life in primary caregivers of patients with metastatic cancer. It was concluded that primary caregivers of breast cancer patients have more anxiety than those of non-cancer patients. They proposed that health care personnel consider screening of psychological symptoms and quality of life in primary caregivers of patients with cancer [19].

Currently, there is a great number of patients diagnosed with breast cancer in Iran and investigators have observed anxiety symptoms in patients' spouses. However, to the best of our knowledge, no previous study investigated the psychological problems these spouses have to face. Therefore, we decided to conduct an investigation with the aim of determining anxiety levels and quality of life scores of spouses of patients with breast cancer and those of healthy women and comparing them between these two groups of spouses.

\section{MATERIALS AND METHODS}

This research was a case control study. The statistical population was all the spouses of patients with breast cancer undergoing chemotherapy. The samples consisted of 95 husbands of breast cancer patients who went to the chemotherapy unit of Shahid-Motahary clinic (under the supervision of Shiraz University of Medical Sciences) and passed the criteria of the study samples. In the control group, 95 spouses of healthy wives were chosen. In both the case and control groups, sampling was simple and based on inclusion criteria. Inclusion criteria for the case group were diagnosis of breast cancer in their wives, receiving chemotherapy for at least for 3 months and willingness to participate in the study. In the control group, inclusion criteria were willingness to participate and wives with no known chronic disease. In the case group, reluctance to fill out the questionnaire and in the control group, unwillingness to cooperate in the study were the exclusion criteria.

Data collecting tools included questionnaires covering demographic information of samples, short form quality of life questionnaire of World Health Organization (WHO) and Beck anxiety questionnaire. Validity and reliability of both of questionnaires have been determined in many studies in Iran and have been used for research on various groups. Beck anxiety questionnaire with a validity value of 0.72 and a reliability value of 0.83 [20] and health survey questionnaire with a reliability value of 0.7 to 0.9 have been confirmed for the Iranian society [21]. Beck anxiety questionnaire has 21 questions with 4 parts of Likert scales whose scores vary from 0 to 63. Scores of 0 to 7 indicate slight or no anxiety, 8 to 15 low anxiety, 16 to 25 moderate anxiety and 26 to 63 high anxiety [20]. 
Mahboobeh Magharei et al. "Comparison of the Level of Anxiety and Quality of Life among Spouses of Women with Breast Cancer and Healthy Women"

Short-form health survey questionnaire of WHO is a shortened form of WHO quality of life questionnaire with 100 items which evaluates life quality in 4 health related fields including physical health, psychological, social interactions and life environment. This questionnaire has 26 questions and the first and second generally asks about life quality and health status. Next 24 items revolve around the 4 aforementioned fields [21]. Data were analyzed by SPSS software and methods of descriptive statistics, independent $t$ test, Chi-square and one-way analysis of variance tests.

\section{RESULTS}

At the time of the study, all the participants including case and control member were married and living with their wives. Duration of breast cancer in wives of the case group varied from 3 to 144 months. The average age of participants was $41.2 \pm 10.2$. From an education level standpoint, 79 $(41.8 \%)$ of participants had bachelor's degree or higher. 85 persons $(45 \%)$ were self-employed and the average number of children in each family was two. 31 (16.4\%) of participants' wives were employed. the highest education level in the wives was high school diploma with 68 cases (36\%). Statistical independent t-test showed no difference between the two groups except for age. The average age of the case group was higher but the other variables were similar when comparing the two groups. Table 1 displays demographic variables of case and control groups.

Table1. Comparison of the demographic variables of cases and controls

\begin{tabular}{|c|c|c|c|c|}
\hline & Group & Mean & Std. Deviation & Sig \\
\hline \multirow[t]{2}{*}{ Job } & Case & 2.25 & 1.320 & \multirow{2}{*}{0.72} \\
\hline & Control & 2.04 & 1.106 & \\
\hline \multirow[t]{2}{*}{ Age } & Case & 42.78 & 11.523 & \multirow{2}{*}{0.02} \\
\hline & Control & 39.71 & 8.690 & \\
\hline \multirow[t]{2}{*}{ Education } & Case & 3.54 & 1.059 & \multirow{2}{*}{0.27} \\
\hline & Control & 3.77 & 1.288 & \\
\hline \multirow[t]{2}{*}{ Marital duration } & Case & 19.08 & 9.623 & \multirow{2}{*}{0.45} \\
\hline & Control & 12.60 & 9.148 & \\
\hline \multirow[t]{2}{*}{ Number of children } & Case & 2.62 & 1.385 & \multirow{2}{*}{0.31} \\
\hline & Control & 2.55 & 1.063 & \\
\hline \multirow[t]{2}{*}{ Wife job } & Case & 4.43 & 1.217 & \multirow{2}{*}{0.24} \\
\hline & Control & 4.51 & 1.085 & \\
\hline \multirow[t]{2}{*}{ Wife education } & Case & 3.07 & 1.370 & \multirow{2}{*}{0.51} \\
\hline & Control & 3.57 & 0.861 & \\
\hline
\end{tabular}

Average scores of quality of life were $84.5 \pm 14.1 \%$ and $87.2 \pm 12.6 \%$. For the case and control groups, respectively. Except for social relationships and environment domains, no statistically significant differences were observed between the two groups. Table 2 illustrates score comparison of the various domains of quality of life and the overall quality of life scores in case and control groups.

Table2. Comparison of the domains of quality of life and the overall scores in case and control groups

\begin{tabular}{|c|c|c|c|c|c|}
\hline Variable & Group & $\mathrm{N}$ & Mean & Std. Deviation & Sig \\
\hline \multirow[t]{2}{*}{ Physical health } & Case & 95 & 26.07 & 4.265 & \multirow{2}{*}{0.81} \\
\hline & Control & 95 & 27.81 & 4.116 & \\
\hline \multirow[t]{2}{*}{ Psychological } & Case & 95 & 21.40 & 3.874 & \multirow{2}{*}{0.57} \\
\hline & Control & 95 & 22.15 & 3.661 & \\
\hline \multirow[t]{2}{*}{ Social relations } & Case & 95 & 25.68 & 7.132 & \multirow{2}{*}{0.00} \\
\hline & Control & 95 & 11.25 & 1.934 & \\
\hline \multirow[t]{2}{*}{ Life circumstance } & Case & 95 & 11.31 & 4.110 & \multirow{2}{*}{0.00} \\
\hline & Control & 95 & 26.17 & 5.212 & \\
\hline \multirow[t]{2}{*}{ Quality of life } & Case & 95 & 84.57 & 14.187 & \multirow{2}{*}{0.17} \\
\hline & Control & 95 & 87.28 & 12.682 & \\
\hline
\end{tabular}

One-way analysis of variance test showed that in the case and control groups, there was a statistical relation between the overall quality of life score and the level of anxiety. At all the levels of anxiety in the case group, anxiety was higher and life quality was lower. Life quality in controls group was better due to lower levels of anxiety $(\mathrm{p}=0.04)$. Table 3 shows anxiety scores in the case and control groups. 
Mahboobeh Magharei et al. "Comparison of the Level of Anxiety and Quality of Life among Spouses of Women with Breast Cancer and Healthy Women"

Table3. Frequency distribution and mean scores of anxiety in the case and control groups

\begin{tabular}{|c|c|c|c|c|c|c|c|c|c|}
\hline Group & Anxi & & & & & & & & \\
\hline & $\begin{array}{l}\text { Low } \\
\text { M }\end{array}$ & D & $\begin{array}{l}\text { Weal } \\
\text { M }\end{array}$ & SD & $\begin{array}{l}\text { Mod } \\
\text { M }\end{array}$ & SD & $\begin{array}{l}\text { Seve } \\
M\end{array}$ & SD & Sig \\
\hline $\begin{array}{l}\text { Case } \\
\text { Control }\end{array}$ & $\begin{array}{l}94.0 \\
93.0\end{array}$ & $\begin{array}{l}11.8 \\
11.8\end{array}$ & $\begin{array}{l}87.9 \\
85.6\end{array}$ & $\begin{array}{l}12.9 \\
9.2\end{array}$ & $\begin{array}{l}83.9 \\
79.1\end{array}$ & $\begin{array}{l}13.2 \\
11.3\end{array}$ & $\begin{array}{l}87.2 \\
72.5\end{array}$ & $\begin{array}{l}12.6 \\
11.3\end{array}$ & 0.04 \\
\hline
\end{tabular}

Furthermore, one-way analysis of variance indicated significant statistical difference between anxiety levels in the two groups. The mean score of anxiety in the case group was higher $(\mathrm{p}<0.001)$.

Pearson correlation coefficient revealed a statistical relation between the average anxiety and quality of life scores in a way that higher anxiety scores corresponded to low quality of life scores $(p<0.001)$.

In regard to the correlation between studied variables and anxiety and quality of life scores, Pearson correlation coefficient showed that in the case group, chemotherapy history and average anxiety scores $(p<0.02)$ were related. It was also shown that there was a relation between the number of children and average overall quality of life score $(\mathrm{p}<0.02)$. Also in the control group, no significant relation was observed between demographic variables and average anxiety and quality of life scores.

One way analysis of variance test indicated that in both groups, low anxiety levels corresponded to high quality of life scores. $(\mathrm{p}<0.01)$. It also showed that in the case group, there was a relation between anxiety and quality of life scores $(\mathrm{p}<0<0.01)$.

\section{DISCUSSION}

In cancer treatment, there is a growing emphasis on attention to psychological and social needs of patients and their families. Occasionally, family members are considered second-hand patients due to high stress levels seen in them, which can potentially interfere with their caregiving roles [22].

In this regard, researchers have paid extensive attention to the spouses of women with breast cancer, because, their distress is as much as patients or even more [23].

The current study was conducted with the aim of comparing anxiety levels and quality of life scores among spouses of women with breast cancer and those of healthy women.

In this investigation, no significant statistical relation was found between demographic variables and disease features with mean quality of life scores in the case group. But in the study of Iqbal et al (2001), it was shown that anxiety levels were higher among spouses with low socioeconomic status and individuals who were less educated [17].

Results of this study revealed that anxiety in spouses of patients with breast cancer was higher than that of the control group. Grov et al (2005) concluded that primary caregivers had more anxiety levels than normal samples in a research with the goal of examining anxiety, depression, and quality of life of primary caregivers of patients with metastatic cancer [19].

Furthermore, Iqbal et al (2001) performed a study to determine the incidence of anxiety in 100 spouses of under chemotherapy patients with breast cancer through Taylor anxiety scale. They reported that $64 \%$ of their spouses dealt with anxiety [17].

Sergin et al (2007) found that anxiety in the women with breast cancer and their spouses had a consistent correlation in their study on 96 couples including women with breast cancer and their husbands [24].

In the current study, mean overall quality of life scores indicated no significant statistical difference between the two groups. However, Aydogan et al. (2016) concluded that there is a significant difference in quality of life between caregivers of patients with cancer and the control group [16]. It seems that quality of life is affected by differences in emotional, cultural, economic and social aspects in different communities.

In the present study, a significant statistical difference was observed between the two groups in social relationships and environment domains. Whereas in the investigation of Wagner et al (2006), it was found out that spouses of patients with breast cancer had lower quality of life scores than the control group, especially in general health, vitality, emotional role and mental health subscales [23]. 
Mahboobeh Magharei et al. "Comparison of the Level of Anxiety and Quality of Life among Spouses of Women with Breast Cancer and Healthy Women"

\section{CONCLUSION}

According to the results of this study, anxiety levels in husbands of women with breast cancer were seen to be higher than the anxiety of spouses of healthy women. Due to the exclusive role of spouses in serving and supporting these women, it is necessary to evaluate emotional distresses to create an appropriate strategy to decrease anxiety and improve quality of life in these people.

Despite the fact that a significant statistical difference between the overall life quality score for the spouses of women with breast cancer and those of healthy women was not found, a significant difference was observed in social relationships and environment domains.

\section{ACKNOWLEDGEMENT}

The authors would like to thank all the participants in this study, personnel of chemotherapy unit of Shahid-Motahary clinic (under the supervision of Shiraz University of Medical Sciences) as well as colleagues of the clinical research center of Nemazee hospital who helped us in the statistical analysis of data.

\section{REFERENCES}

[1] Martha E. Langhorne, Janet S. Fulton, Shirley E. Otto, editors. Oncology nursing. Mosby Incorporated; 2007.

[2] Kearney N, Richardson A. Nursing patients with cancer: principles and practice. Elsevier Health Sciences; 2006.

[3] Graham A Colditz, MD, Niess-Gain. Breast Cancer Epidemiology and Risk Factors. 2015. available at: http://emedicine.medscape.com/article/1697353-overview

[4] Harirchi I, Karbakhsh M, Kashefi A, Momtahen AJ. Breast cancer in Iran: results of a multicenter study. Asian pacific journal of cancer prevention. 2004 Jan 1;5(1):24-7.

[5] The American Cancer Society medical and editorial content team. Anxiety, Fear, and Depression: Having cancer affects your emotional health. 2016. available at: https://www.cancer.org/treatment/treatments-and-side-effects/emotional-side-effects/anxietyfear-depression.html\#written_by

[6] Hjerl K, Andersen EW, Keiding N, Mortensen PB, Jørgensen T. Increased incidence of affective disorders, anxiety disorders, and non-natural mortality in women after breast cancer diagnosis: a nation-wide cohort study in Denmark. Acta Psychiatrica Scandinavica. 2002 Apr $1 ; 105(4): 258-64$.

[7] Lewis FM, Zahlis EH, Shands ME, Sinsheimer JA, Hammond MA. The functioning of single women with breast cancer and their school-aged children. Cancer practice. 1995 Dec;4(1):1524.

[8] Sandgren AK, Mullens AB, Erickson SC, Romanek KM, McCaul KD. Confidant and breast cancer patient reports of quality of life. Quality of Life Research. 2004 Feb 1;13(1):155-60.

[9] Northouse LL. Breast cancer in younger women: effects on interpersonal and family relations. Journal of the National Cancer Institute. Monographs. 1993 Dec (16):183-90.

[10] Grunfeld E, Coyle D, Whelan T, Clinch J, Reyno L, Earle CC, Willan A, Viola R, Coristine M, Janz T, Glossop R. Family caregiver burden: results of a longitudinal study of breast cancer patients and their principal caregivers. Canadian Medical Association Journal. 2004 Jun 8;170(12):1795-801.

[11] Vincent T. De Vita-Cancer Principles and practice of oncology. Ediţia a Va. 1999;35.

[12] Schumacher KL, Dodd MJ, Paul SM. The stress process in family caregivers of persons receiving chemotherapy. Research in nursing \& health. 1993 Dec 1;16(6):395-404.

[13] Wells-Di Gregorio S, Carpenter KM, Dorfman CS, Yang HC, Simonelli LE, Carson III WE. Impact of breast cancer recurrence and cancer-specific stress on spouse health and immune function. Brain, behavior, and immunity. 2012 Feb 29;26(2):228-33. 
Mahboobeh Magharei et al. "Comparison of the Level of Anxiety and Quality of Life among Spouses of Women with Breast Cancer and Healthy Women"

[14] Ferrans CE. Development of a quality of life index for patients with cancer. In Oncology nursing forum 1989 Dec (Vol. 17, No. 3 Suppl, pp. 15-9).

[15] Petrie W, Logan J, DeGrasse C. Research review of the supportive care needs of spouses of women with breast cancer. InOncology nursing forum 2001 Nov 1 (Vol. 28, No. 10).

[16] Aydogan U, Doganer YC, Komurcu S, Ozturk B, Ozet A, Saglam K. Coping attitudes of cancer patients and their caregivers and quality of life of caregivers. Indian journal of palliative care. 2016 Apr;22(2):150.

[17] Iqbal A, Qureshi A, Siddiqui KS. The Incidence of Anxiety among Spouses of Breast Cancer Patients. Nine. 2001;22:67.

[18] Bigatti SM, Brown LF, Steiner JL, Miller KD. Breast cancer in a wife: How husbands cope and how well it works. Cancer Nursing. 2011 May 1;34(3):193-201.

[19] Grov EK, Dahl AA, Moum T, Fosså SD. Anxiety, depression, and quality of life in caregivers of patients with cancer in late palliative phase. Annals of oncology. 2005 Jul 1;16(7):1185-91.

[20] Kaviani H, Mousavi AS. Psychometric properties of the Persian version of Beck Anxiety Inventory (BAI). Tehran University Medical Journal TUMS Publications. 2008 May 15;66(2):136-40.

[21] Nejat S, Montazeri A, Halakuyi Nayini K, Kazem M, Majd Zadeh SR. Validation and normalization world health organization quality of life questionnaire. Scientific Journal of School of Public Health and Institute of Public Health Research. 2006;4(4):1-2.

[22] Page AE, Adler NE, editors. Cancer care for the whole patient: meeting psychosocial health needs. National Academies Press; 2008 Apr 19.

[23] Wagner CD, Bigatti SM, Storniolo AM. Quality of life of husbands of women with breast cancer. Psycho-Oncology. 2006 Feb 1;15(2):109-20.

[24] Sergin C, Badger T, Dorros SM, Meek P,Lopez AM. Interdependent anxiety and psychological distress in women with breast cancer and their partners. Psycho-Oncology. $2007 \mathrm{Jul}$ $1 ; 16(7): 634-43$ 